\title{
Effects of species misidentification on population assessment of overfished white marlin Tetrapturus albidus and roundscale spearfish $T$. georgii
}

\author{
Lawrence Beerkircher $^{1, *}$, Freddy Arocha ${ }^{2}$, Ann Barse ${ }^{3}$, Eric Prince ${ }^{1}$, \\ Victor Restrepo ${ }^{4}$, Joseph Serafy ${ }^{1}$, Mahmood Shivji ${ }^{5, *}$ \\ ${ }^{1}$ Southeast Fisheries Science Center, 75 Virginia Beach Drive, Miami, Florida 33149, USA \\ ${ }^{2}$ Instituto Oceanografico, Universidad de Oriente, Cerro Colorado 204 Cumana, Venezuela \\ ${ }^{3}$ Salisbury University, Department of Biological Sciences, 1101 Camden Avenue, Salisbury, Maryland 21801, USA \\ ${ }^{4}$ International Commission for the Conservation of Atlantic Tunas, Corazón de María 8, 28002 Madrid, Spain \\ ${ }^{5}$ Guy Harvey Research Institute, Oceanographic Center, Nova Southeastern University, 8000 N. Ocean Drive, \\ Dania Beach, Florida 33004, USA
}

\begin{abstract}
The white marlin Tetrapturus albidus (Istiophoridae) is considered to be among the most overexploited species under international management jurisdiction in the Atlantic Ocean, resulting in diverse stakeholder concerns. Efforts have been made to add it to the US Endangered Species List. Its population status has become uncertain with the realization that: (1) longstanding misidentifications of white marlin have occurred with the recently recognized, morphologically similar and sympatric roundscale spearfish $T$. georgii; and (2) the 2 species have unknowingly been assessed and managed as a species group. We show that roundscale spearfish currently constitute a substantial proportion $(\sim 27 \%)$ of the overall 'white marlin' catch in the western North Atlantic, with high spatial variation within this region. Consequently, the accuracy of current biological knowledge on white marlin, some of which has formed the input for past population status modeling, is compromised by 'contamination' due to misidentification. Population assessment simulations in the western North Atlantic incorporating the proportion of roundscale spearfish $(27 \%)$ were run; these indicated that historical changes in the ratio of the 2 species, as well as differences in the population growth rates between $T$. albidus and T. georgii, affect simulation results. Our findings suggest misidentifications between the species may have affected the accuracy of past $T$. albidus population assessments in the western North Atlantic, which therefore need re-visiting to permit improved management and recovery of this species. New collection of life history data for T. albidus and T. georgii is also recommended to corroborate the results of historical studies.
\end{abstract}

KEY WORDS: Population assessments $\cdot$ Roundscale spearfish $\cdot$ Species identification $\cdot$ White marlin

\section{INTRODUCTION}

The white marlin Tetrapturus albidus (= Kajikia albida. Collette et al. 2006; Istiophoridae) is considered among the most overexploited pelagic fishes under international management jurisdiction in the Atlantic. Taken primarily as bycatch on longline fishing gear targeting tuna and swordfish, white marlin is also the target of a multimillion dollar recreational fishing industry (Jesien et al. 2006). Recent population assessments (ICCAT 2003) have indicated that white marlin biomass ( $B$; metric tons) has declined to about $12 \%$ of the level necessary to produce maximum sustainable yield $\left(B_{\mathrm{MSY}}\right)$. Therefore, the population status and outlook for white marlin is of intense management and socioeconomic concern, and it has been petitioned for listing under the US Endangered Species Act (WMBRT 2007). 
Morphologically, the white marlin is very similar to the sympatric istiophorid Tetrapturus georgii (roundscale spearfish), which has only recently been validated genetically (Shivji et al. 2006). The distinguishing morphological differences are subtle, raising the troubling prospect that fishers and scientists have been misidentifying the previously unrecognized roundscale spearfish as white marlin, probably for decades (Shivji et al. 2006, Beerkircher et al. 2008). Assessing the status of white marlin populations and attendant formulation of management and conservation policy relies heavily on fishery-dependent catch information from commercial and recreational fishers. Thus, species misidentification represents a heretofore unrecognized source of uncertainty for fishery scientists and other stakeholders directly or indirectly affected by white marlin population assessments.

Incorrect species catch records may be of little consequence to management and conservation if proportions of roundscale spearfish to white marlin are very small, and are spatially and temporally consistent throughout the species' range. Under this scenario, the inadvertent management of both species as a complex may still provide valid estimation of white marlin population status. However, a recent study using morphological identification of marlin bycatch in the US commercial fishery between 1993 and 2006 suggested that roundscale spearfish abundance is not trivial (Beerkircher et al. 2008). Evidence is absent that the species proportions are, or have been historically, homogeneous in space and time. Complicating the issue of white marlin population assessments is that spatiotemporal patterns of fishing effort over the range of the 'white marlin' (now recognized as a combination of Tetrapturus albidus and T. georgii) have changed substantially over time (Serafy et al. 2004). This change in fishing effort patterns leaves open the possibility that fishing mortality for both species has also changed.

Determining the current and historical proportions of roundscale spearfish and white marlin and evaluating potential impacts of long-term misidentifications on population assessments are important given the socioeconomic, policy, and legal ramifications of misidentification for the commercial and recreational fishing sectors, international management organizations, and conservation groups. Here we: (1) employ DNA analysis to validate the morphological identifications used by Beerkircher et al. (2008), (2) present further evidence that roundscale spearfish abundances are not trivial relative to white marlin in the western North Atlantic, (3) show that catch proportions of roundscale spearfish are spatially heterogeneous within this region, and (4) show by population assessment simulation exercises that long-standing misiden- tification of roundscale spearfish as white marlin may have considerable consequences for management and conservation of both species.

\section{MATERIALS AND METHODS}

Two main information sources were examined to derive proportions of roundscale spearfish: (1) data on istiophorid bycatch collected by scientific observer personnel (hereafter 'observer[s]') on commercial Atlantic pelagic longline fishing vessels (Arocha \& Marcano 2001, Keene et al. 2007), and (2) marlins brought to shore (hereafter 'landed') during USA east coast recreational white marlin tournaments.

Three subsets of the observer-collected catch data were considered: (1) US1, comprised data collected by a single observer in the US Pelagic Observer Program (POP) who was especially adept at differentiating Tetrapturus spearfishes from white marlin; these data encompassed 144442 hooks observed from 1996 to 2006; (2) US2, comprised data taken after enhanced spearfish identification training was instituted for all (59) POP observers working from January 2007 through June 2008 (1331332 hooks observed); (3) VZL, was collected by 2 experienced observers with the Venezuelan Pelagic Longline Observer Program from 2002 to 2007 (1 114943 hooks observed). All observer identifications of roundscale spearfish were achieved using the diagnostic morphometrics described by Beerkircher et al. (2008), with a subset (see below for specifics) verified by DNA analysis. Tissue samples for the VZL subset were not retained.

The White Marlin Open (WMO) recreational fishing tournaments were held in Ocean City, Maryland (USA) in August 2007 and 2008. Tissue samples were collected from 11 of the 15 'white marlin' landed in 2007 and all 11 'white marlin' landed in 2008. All tournament specimens were initially identified based on morphological criteria reported by Beerkircher et al. (2008).

We assessed the accuracy of the morphological identifications in the US1, US2, and WMO datasets by sequencing the mitochondrial NADH subunits $4 \mathrm{~L}-4$ (ND4L-ND4) genes (methods in Shivji et al. 2006) of a subset (see 'Results') of the observer specimens and all tournament samples. These sequences were compared to reference sequences from white marlin and roundscale spearfish (Shivji et al. 2006). The large (5.5\%) sequence divergence at this locus between the 2 species and unequivocal reciprocal monophyly of each (Shivji et al. 2006) made distinguishing the 2 species' sequences unambiguous.

For all 4 datasets, the proportion of roundscale spearfish was calculated for each US National Marine 
Fisheries Service (NMFS) Highly Migratory Species Statistical Area where data were available (Fig. 1, see Keene et al. 2007 for NMFS area details). Datasets were also pooled by area, and 95\% confidence intervals about proportions (Brown et al. 2001) were calculated. To reveal statistical differences among areas, we conducted pairwise comparisons of proportions of roundscale spearfish using standard chi-squared tests.

The potential impact of misidentification on perceived population status for the 2 species was examined through simulation, whereby the most recent benchmark assessment for Atlantic white marlin (ICCAT 2003) was assumed to be an accurate estimate of the biomass (as percent of $B_{\mathrm{MSY}}$ ) trajectory for the 2 species combined. The simulation was based on a Schaefer-type production model fitted with the ASPIC software (Prager 1994), which is the same model used in the assessment. Specifically, we used the results for the assessment model known as the retrospectivelyadjusted base run (Run 36 in Table 7 of ICCAT 2003; model biomass and yield trajectories are presented in Appendix 1.

We generated 5 simple contrasting time series (hereafter 'scenarios') of yields for the species' populations spanning 1955 to 2001 . The 5 simulated scenarios for the proportion of roundscale spearfish were: constant; increasing linearly; decreasing linearly; step up, down; decreasing steps. We then estimated population-specific parameters (intrinsic population growth rate and

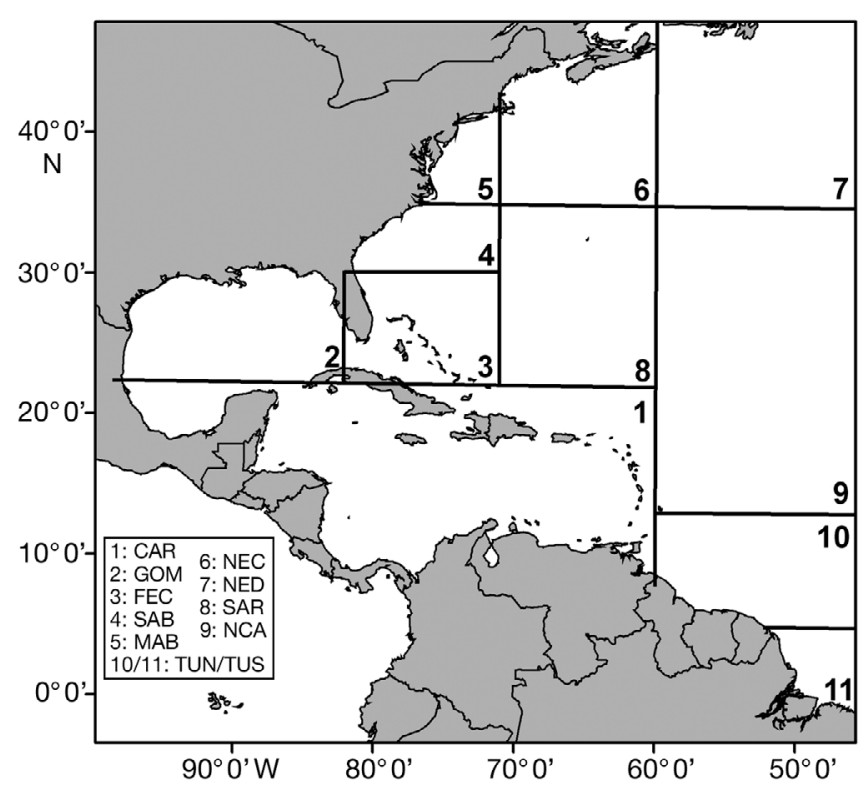

Fig. 1. US National Marine Fisheries Service Highly Migratory Species Statistical Areas of the western North Atlantic used in the present study. CAR: Caribbean; GOM: Gulf of Mexico; FEC: Florida East Cosat; SAB: South Atlantic Bight; MAB: Mid-Atlantic Bight; NEC: Northeast Coast; NED: Northeast Distant; SAR: Sargasso Sea; NCA: North Central Atlantic; TUN/TUS: Tuna North/Tuna South population carrying capacity) that would result in population trajectories that, when combined, would match the biomass trajectory given by the benchmark assessment. To accommodate the absence of reliable growth rate information for each of the species, we used 2 different growth rate projections (i.e. different growth rates and the same growth rate) in the simulations.

To identify the model parameters, we let the superscripts $R, W$, and $T$ denote roundscale spearfish (RSS), white marlin (WHM), or total (RSS+WHM), respectively, and let the subscript $t$ denote year. The time series of total yield ${ }^{T} Y_{t}$ and total biomass ${ }^{T} B_{t}$ are fixed (Table A1). The simulation approach was as follows: (1) generate hypothetic yield trajectories ${ }^{R} Y_{t}$ and ${ }^{W} Y_{t_{t}}$ constrained to add up to ${ }^{T} Y_{t i}$ (2) estimate the parameters ${ }^{R} r_{1}{ }^{W} r_{1}{ }^{R} K$, and ${ }^{W} K$ that minimize

$$
\begin{aligned}
& \sum_{\mathrm{y}=1956}^{2001}\left[{ }^{T} B_{t}-\left({ }^{R} B_{t}+{ }^{W} B_{t}\right)\right]^{2}+ \\
& \sum_{\mathrm{y}=1956}^{2000}\left[{ }^{T} Y_{t}-\left({ }^{R} \hat{Y}_{t}+{ }^{W} \hat{Y}_{t}\right)\right]^{2}
\end{aligned}
$$

where ${ }^{R} B_{1956}={ }^{R} K$ and ${ }^{W} B_{1956}={ }^{W} K$, and for other years, biomass is predicted by the equations

$$
{ }^{R} B_{t+1}={ }^{R} B_{t}+{ }^{R} r{ }^{R} B_{t}\left(1-\frac{{ }^{R} B_{t}}{{ }^{R} K}\right)-{ }^{R} Y_{t}
$$

and

$$
{ }^{{ }^{W}} B_{t+1}={ }^{w_{B}} B_{t}+{ }^{{ }} r{ }^{w_{B}}\left(1-\frac{{ }^{w_{B}}}{{ }^{w_{K}}}\right)-{ }^{{ }^{W}} Y_{t}
$$

For each scenario, 2 sets of population projections were made. In 1 set, 4 of the population parameters ${ }^{R} r_{\text {, }}$ ${ }^{W_{r}}{ }^{R} K$, and ${ }^{W} K$ were estimated independently. In the other, the 2 population growth rates were assumed to be the same, in order to allow for the possibility that the 2 species have similar life histories. The population growth rates were estimated in our minimization routine, with initial values set equal to that estimated in the ICCAT (2003) white marlin stock assessment.

The second term in Eq. (1) was added to avoid cases in which the projections for either population would predict a stock collapse. The predicted model yields were set equal to 0 if the population collapsed, such that the quadratic term would be large, thus penalizing the solution. Otherwise, the predicted yields were calculated from the basic population dynamics equation, such that the quadratic term would be 0 . For example, for white marlin:

$$
{ }^{w} \hat{Y}_{t}= \begin{cases}0, & { }^{w} B_{t+1} \leq 0 \\ { }^{w} Y_{t}, & { }^{w} B_{t+1}>0\end{cases}
$$

The minimization was carried out in MS Excel. All hypothetical yield trajectories were constructed such that the fraction of the yield corresponding to roundscale spearfish in the last year was 0.27 , i.e. the overall proportion given in Table 1 . 
Table 1. Tetrapturus georgii and T. albidus. Fishing effort (no. hooks observed), numbers of roundscale spearfish and white marlin, and proportion of roundscale spearfish in the 2-species management group for each US National Marine Fisheries Service Statistical Area in the western North Atlantic. See Fig. 1 for area abbreviations. LCL and UCL: lower and upper 95\% (binomial) confidence limits

\begin{tabular}{|c|c|c|c|c|c|c|}
\hline Area & Effort & T. georgii & T. albidus & $\begin{array}{c}\text { Proportion of } \\
\text { T. georgii }\end{array}$ & LCL & UCL \\
\hline CAR & 1030253 & 283 & 563 & 0.335 & 0.334 & 0.397 \\
\hline GOM & 1001528 & 0 & 96 & 0.000 & 0.000 & 0.038 \\
\hline FEC & 84815 & 24 & 37 & 0.393 & 0.281 & 0.519 \\
\hline $\mathrm{SAB}$ & 68893 & 9 & 27 & 0.250 & 0.138 & 0.411 \\
\hline MAB & $112046+2^{\mathrm{a}}$ & 10 & 38 & 0.208 & 0.117 & 0.343 \\
\hline $\mathrm{NEC}$ & 46198 & 14 & 19 & 0.424 & 0.272 & 0.592 \\
\hline NED & 38468 & 4 & 0 & 1.000 & 0.510 & 1.000 \\
\hline SAR & 115145 & 39 & 57 & 0.406 & 0.313 & 0.506 \\
\hline NCA & 22716 & 10 & 3 & 0.769 & 0.497 & 0.918 \\
\hline TUN/TUS & 57127 & 3 & 207 & 0.014 & 0.005 & 0.041 \\
\hline Total & $2577189+2^{a}$ & 396 & 1047 & 0.274 & & \\
\hline
\end{tabular}

\section{RESULTS}

In total, 396 roundscale spearfish and 1047 white marlin were observed from 1993 to 2008 in the western North Atlantic (Table 1). Of the 105 roundscale spearfish reported in the US1 and US2 datasets, all available archived tissue samples (47 ind.) were confirmed by DNA analysis to be roundscale spearfish. Due to many more available white marlin samples, a random subset of 52 ind. (14\% of all the white marlin in the US1 and US2 data sets) were sequenced; 51 were confirmed as white marlin. Haplotype sequences for both roundscale spearfish and white marlin are available in GenBank (accession nos. GU055177-GU055193). The sole animal incorrectly identified (in the US2 data set) as a white marlin was genetically determined to be a sailfish Istiophorus platypterus, but the specimen had been badly shark-bitten and was not intact.

The US1 dataset contained information for 8 of the 10 NMFS Statistical Areas. Roundscale spearfish occurred in 6 of these areas (Fig. 2); they were exclusive in the North Central Atlantic (NCA) and Florida East Coast (FEC) and were observed in greater proportion to white marlin (87\% roundscale spearfish) in the Sargasso Sea (SAR). The US2 dataset contained information for 9 of the 10 NMFS areas; roundscale spearfish were found in 7 areas, were exclusive in the Northeast Distant (NED), were observed in greater proportion to white marlin in the SAR $(86 \%$ roundscale spearfish) and Northeast Coastal (NEC; $54 \%$ roundscale spearfish), and constituted a substantial proportion (>30\% each) in the FEC and South Atlantic Bight (SAB) areas (Fig. 2). The VZL dataset provided information for 4 areas, SAR, NCA, Caribbean (CAR), and
Tuna North/Tuna South (TUN/TUS); these data showed a greater proportion of roundscale spearfish (34\%) in the CAR and a substantially lower value for the SAR $(\sim 2 \%)$ than the other 2 observer data sources. The WMO recreational fishing tournament MidAtlantic Bight (MAB) area, revealed that $31 \%$ of the 'white marlin' landed were roundscale spearfish. Pooling the datasets by area, proportions of roundscale spearfish were only high in the 2 areas with both the lowest observed effort and the lowest amount of each species observed (NED, 100\% roundscale spearfish and NCA, $77 \%$ roundscale spearfish), although several areas with greater amounts of effort observed showed substantial proportions of roundscale spearfish, including the CAR (34\%) and the SAR (41\%; Table 1). Several statistically significant differences in roundscale spearfish proportions emerged among areas (Table 2). The highest uncertainty (i.e. largest confidence intervals) was associated with the 2 highest estimates, a result of low overall bycatch of both species in the NED and NCA areas (Fig. 3). The lowest proportions were for the Gulf of Mexico (GOM) and TUN/TUS areas, which were significantly $(p<0.001)$ lower than those in all 7 other areas (Table 2).

Simulation results (Table 3 ) for the population biomass of the 2 species in 2001 generated under the 5 scenarios for temporal roundscale spearfish to white marlin proportions with either different or identical population growth rates $(r)$ all found white marlin to be overfished, with estimated biomass ranging from 0 to $33 \%$ of $B_{\mathrm{MSY}}$. Simulation results for roundscale spearfish biomass were more variable, ranging from 0 to $144 \%$ of $B_{\mathrm{MSY}}$; with 1 exception, however, all simulations also showed roundscale spearfish to be overfished in 2001. Simulation results for temporal trends 

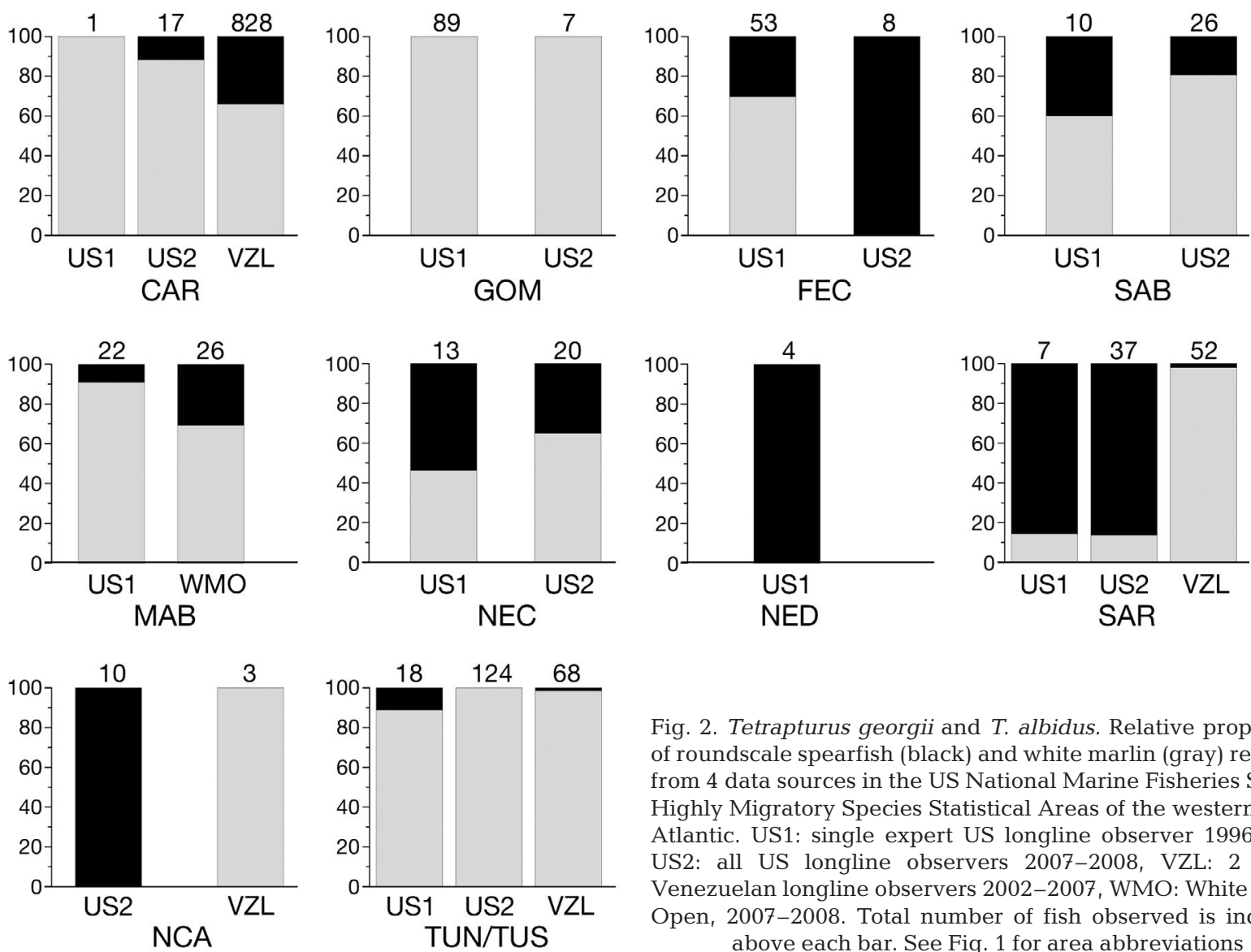

Fig. 2. Tetrapturus georgii and T. albidus. Relative proportions of roundscale spearfish (black) and white marlin (gray) recorded from 4 data sources in the US National Marine Fisheries Service Highly Migratory Species Statistical Areas of the western North Atlantic. US1: single expert US longline observer 1996-2006, US2: all US longline observers 2007-2008, VZL: 2 expert Venezuelan longline observers 2002-2007, WMO: White Marlin Open, 2007-2008. Total number of fish observed is indicated above each bar. See Fig. 1 for area abbreviations

Table 2. Tetrapturus georgii and T. albidus. Pooled dataset results ( $\mathrm{p}$ values; chi-squared test) of pairwise comparisons of proportions of roundscale spearfish in the roundscale spearfish-white marlin species complex in each US National Marine Fisheries Service Statistical Area. Values in bold are significant at $p<0.005$. See Fig. 1 for area abbreviations

\begin{tabular}{|lccccccccc|}
\hline Area & CAR & GOM & FEC & SAB & MAB & NEC & NED & SAR & NCA \\
\hline CAR & 1 & & & & & & & & \\
GOM & $\mathbf{0 . 0 0 0 1}$ & 1 & & & & & & \\
FEC & 0.6589 & $\mathbf{0 . 0 0 0 1}$ & 1 & & & & & \\
SAB & 0.1580 & $\mathbf{0 . 0 0 0 1}$ & 0.1497 & 1 & & & & \\
MAB & 0.0271 & $\mathbf{0 . 0 0 0 1}$ & 0.0384 & 0.6515 & 1 & & & \\
NEC & 0.4902 & $\mathbf{0 . 0 0 0 1}$ & 0.7715 & 0.1251 & 0.0356 & 1 & & \\
NED & 0.0086 & $\mathbf{0 . 0 0 0 1}$ & 0.0176 & 0.0024 & $\mathbf{0 . 0 0 0 6}$ & 0.0296 & 1 & & \\
SAR & 0.4294 & $\mathbf{0 . 0 0 0 1}$ & 0.8732 & 0.0965 & 0.0181 & 0.8562 & 0.0188 & 1 & 1 \\
NCA & 0.0028 & $\mathbf{0 . 0 0 0 1}$ & 0.0136 & $\mathbf{0 . 0 0 1 0}$ & $\mathbf{0 . 0 0 0 1}$ & 0.0349 & 0.2897 & 0.0135 & 1 \\
TUN/TUS & $\mathbf{0 . 0 0 0 1}$ & 0.2393 & $\mathbf{0 . 0 0 0 1}$ & $\mathbf{0 . 0 0 0 1}$ & $\mathbf{0 . 0 0 0 1}$ & $\mathbf{0 . 0 0 0 1}$ & $\mathbf{0 . 0 0 0 1}$ & $\mathbf{0 . 0 0 0 1}$ & $\mathbf{0 . 0 0 0 1}$ \\
\hline
\end{tabular}

(1955 to 2001) in the biomass of the 2 species' populations under each proportion and growth rate scenario (Fig. 4) showed a steeply declining trend in all but one case (roundscale spearfish under Scenario 2, increasing linearly, with different growth rates). It is also notable that with the exception of only 2 simulations (i.e. scenarios projecting roundscale spearfish propor- tions increasing linearly), the temporal decline in roundscale spearfish population size was close to or in many instances greater than that projected for white marlin. Timing of when each species became overfished (i.e. biomass dropped below $B_{\mathrm{MSY}}$ ) was variable, ranging from the mid-1960s to early 1990s, depending on the scenario simulated. The 2 different growth rate 


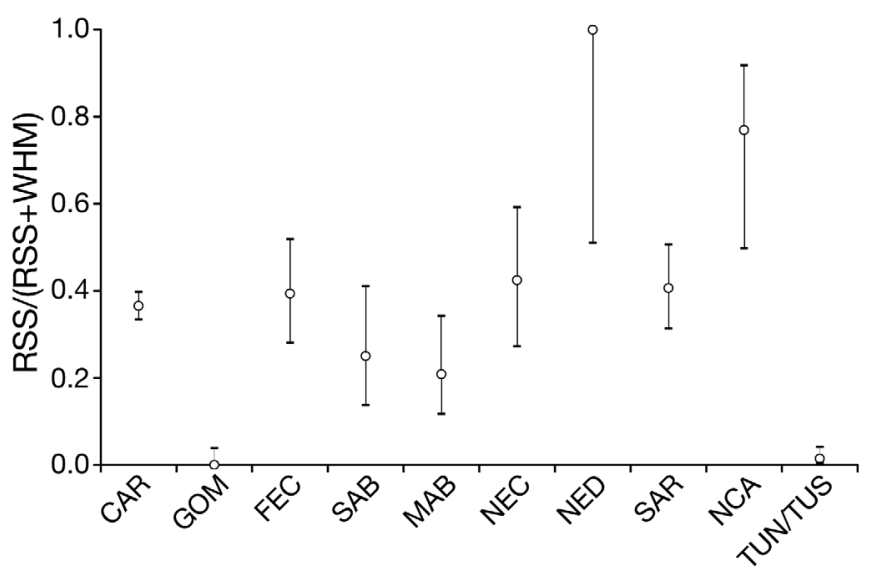

Fig. 3. Tetrapturus georgii and T. albidus. Proportions of roundscale spearfish (RSS) in the RSS-white marlin (WHM) species complex in each US National Marine Fisheries Service Statistical Area. See Fig. 1 for area abbreviations. Error bars represent $95 \%$ confidence intervals

projections clearly affected the perceived biomass status. For example, for each catch proportion scenario considered, the 2001 biomass level was mostly similar for both species when growth rates were assumed to be the same (Table 3, Fig. 4c). In contrast, when growth rates were allowed to differ, the 2001 biomass varied considerably for each catch proportion scenario.

\section{DISCUSSION}

Taxonomic accuracy is fundamental in fish and wildlife monitoring to prevent erroneous assessments and decisions in management and conservation policy. Our genetic validation of the morphological identifications in the US1 and US2 databases leads us to conclude that the morphological characters developed by Beerkircher et al. (2008) are robust, and information in the observer databases used here is accurate. Given this validation, the path is clear for scientists and fishers to accurately distinguish Tetrapturus albidus and $T$. georgii morphologically (in most cases) and provide accurate catch data for population assessments and subsequent policy formulation. The paucity of reliable data sources (i.e. those for which there is confidence in the integrity of the species identifications) resulted in our use of data subsets that were not collected randomly and distributed evenly over both species' ranges. We hope the information presented here will encourage efforts towards accurate species-specific data collection.

\section{Prevalence of roundscale spearfish and spatial proportions}

Overall, roundscale spearfish comprised a substantial proportion $(\sim 27 \%)$ of the roundscale spearfish- white marlin complex in our western North Atlantic datasets. Furthermore, the 2 species are clearly not distributed evenly in this region. Proportions by statistical area suggest that roundscale spearfish are uncommon in the Gulf of Mexico and off the northeastern coast of South America. However, in US east coast and Caribbean waters, they represented 21 to $42 \%$ of the samples; in some areas farther offshore, roundscale spearfish dominated. The large difference in roundscale proportions between the VZL and the other 2 observer datasets in the CAR and SAR areas likely stems from spatiotemporal differences in fishing effort and/or differences in fishing methods employed (e.g. bait type, fishing depth) by the Venezuelan and US commercial fisheries. For example, the VZL data for the SAR were collected in the spring and summer, while the US1 and US2 data were collected in the winter. Further sampling is necessary to resolve this discrepancy, and will also help to resolve uncertainty caused by low sample sizes (observed hooks) in some spatial strata (see Appendix 2 for samples sizes and confidence intervals around proportions of roundscale spearfish for each of the data sets and spatial strata used).

The ramifications of these findings may be substantial in terms of management and conservation policy for white marlin. The accuracy of current biological knowledge on white marlin age and growth, reproduction, feeding habits, migratory patterns, habitat utilization, etc., some of which has formed the input for past population status modeling, may be compromised by 'contamination' due to misidentification with roundscale spearfish. Addi- 
a
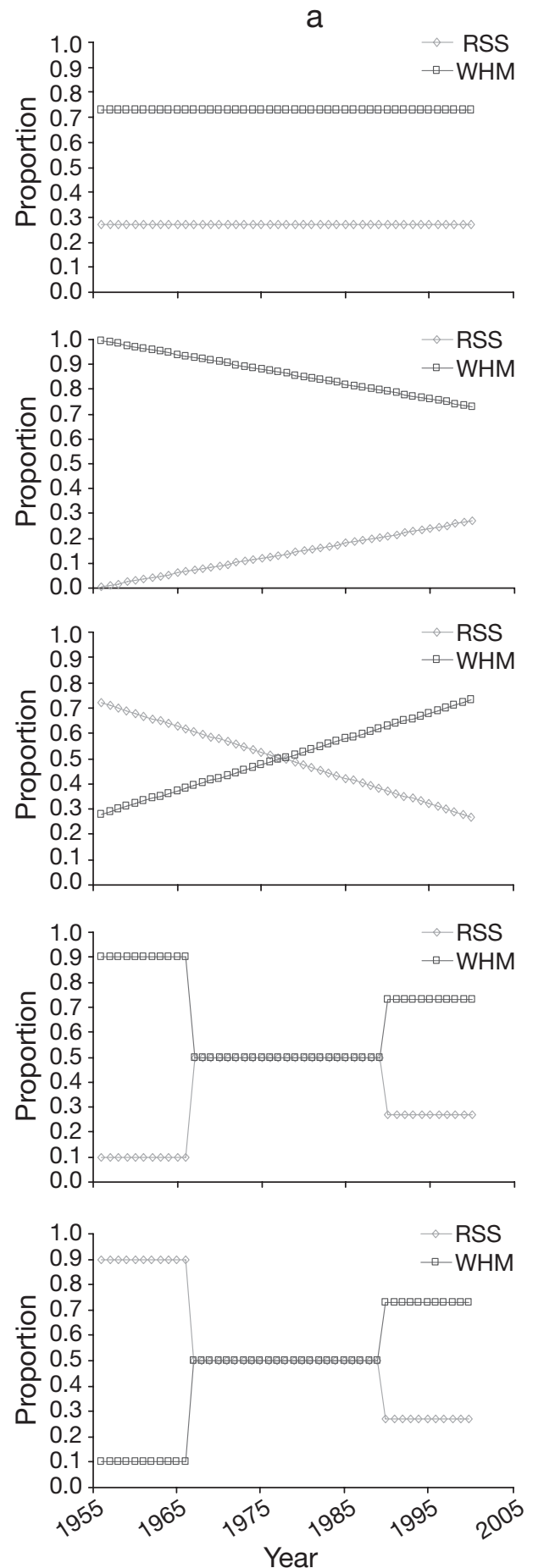

b
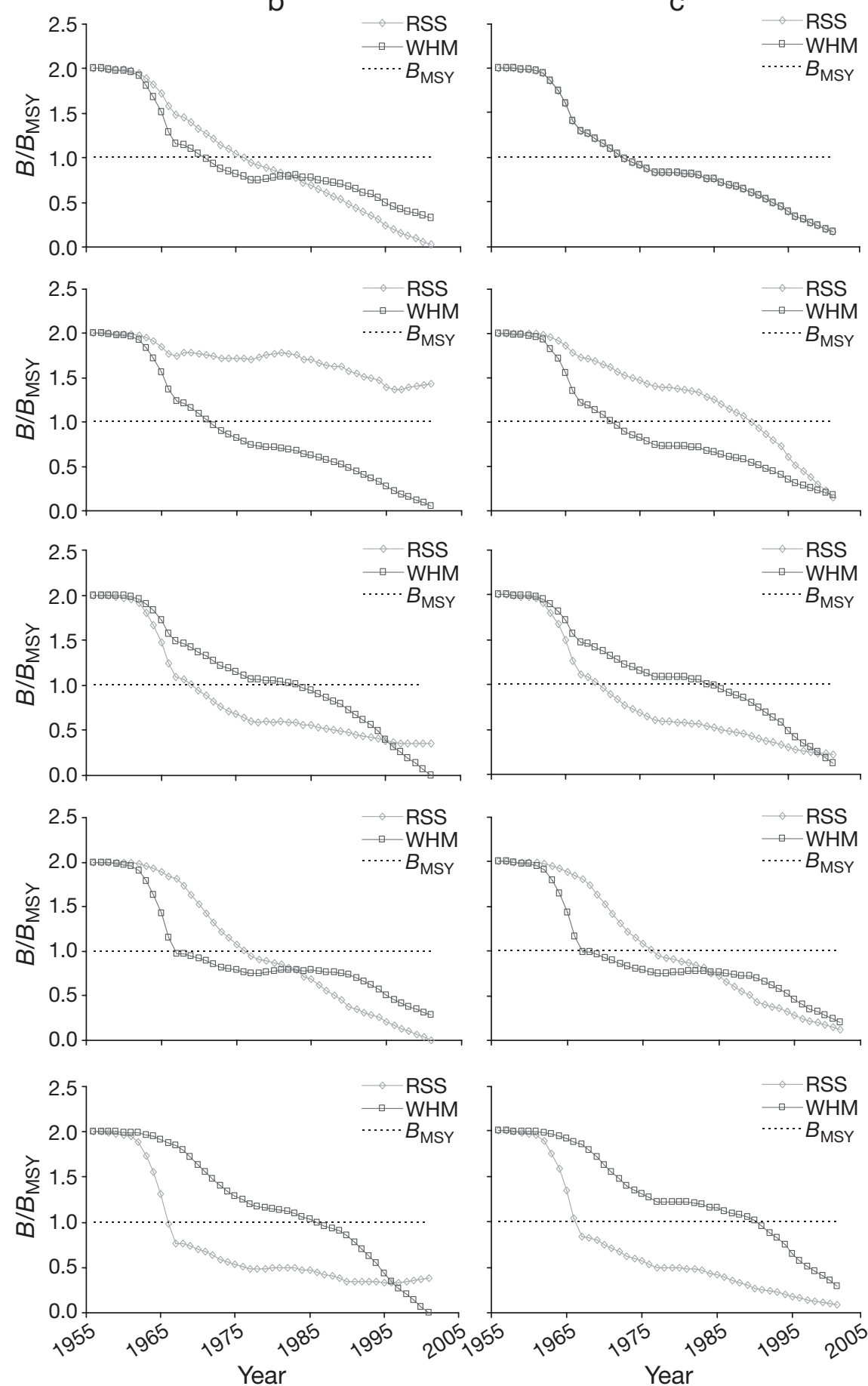

Fig. 4. Tetrapturus georgii and T. albidus. Simulation results of changes in population size of roundscale spearfish (RSS) and white marlin (WHM). Each row corresponds to 1 of 5 scenarios (a) about hypothetical changes in the proportion of the total catch corresponding to RSS: (1) constant; (2) increasing linearly; (3) decreasing linearly; (4) step up, down; (5) decreasing steps. Columns (b) and (c) show the estimated trends in population size, relative to the $B_{\mathrm{MSY}}$ level, for the 2 species assuming (b) different growth rates, or (c) identical growth rates

tionally, assuming no historical change in the overall proportion of roundscale spearfish to white marlin temporally (data are currently unavailable to examine this), then any major spatial redistributions of fishing effort would affect each species differently. For example, a shifting of fishing effort from areas with statistically higher proportions of roundscale spearfish into areas with lower proportions might result in more 
white marlin and fewer roundscale spearfish being removed from the management group. In fact, such a shift has indeed occurred over the last decade in the US pelagic longline fleet (L. Beerkircher unpubl. data).

\section{Population assessment simulations}

Simulation modeling has been shown to be a useful tool in evaluating the potential effects of various assumptions in population assessments (NRC 1998). Our simulations were necessarily limited in scope due to: (1) the lack of reliable species-specific population parameters (growth rate and carrying capacity) for both white marlin and roundscale spearfish, (2) uncertainty as to how the spatial differences in catch proportions may have affected catch per unit effort (CPUE) for each species and, in turn, how changes in CPUE would have affected the population biomass assessments. Further, despite recent genetic evidence that roundscale spearfish also occur in the western South Atlantic (M. Shivji \& F. Hazin unpubl. data), without knowledge of roundscale spearfish to white marlin ratios from this region, our simulation results apply only to roundscale spearfish and white marlin population trends in the western North Atlantic.

These caveats notwithstanding, the simulations are valuable in illustrating how species-specific assessment might deviate from current 'species complex' models. Depending on the scenario used, the 2001 white marlin sensu stricto biomass status in the western North Atlantic ranged from a best case of only $33 \%$ of $B_{\mathrm{MSY}}$ to collapse ( $0 \%$ of $B_{\mathrm{MSY}}$ ), indicating substantial overfishing to a severely depleted population. Although the previous Atlantic-wide assessment conducted in 2002 showed 'white marlin' at $12 \%$ of $B_{\mathrm{MSY}}$ (ICCAT 2003), it may be problematic to use this benchmark in a comparative context as it is only valid for the 2 species combined. Also a cause for concern is that all simulations considering the 2 species separately showed declining historical trajectories for white marlin in the western North Atlantic, despite decades of international management.

Our findings on the prevalence of roundscale spearfish in the context of decades of species misidentification, spatial heterogeneity in proportions of white marlin and roundscale spearfish in the context of spatio-temporal shifts in fishing effort, and impacts of differing species catch proportions and growth rates on population biomass assessments all cast uncertainty on past white marlin assessments. Given these uncertainties and the largely pessimistic population status and trajectories for both species suggested by our simulations, there is a pressing need for further information to improve management, including: (1) accurate and pre- cise, Atlantic-wide estimates of the current proportions of roundscale spearfish within various spatio-temporal strata, (2) data on whether proportions of roundscale spearfish have remained constant historically via genetic testing of archival 'white marlin' biological material, (3) data on the life history, distribution, abundance and movement patterns of roundscale spearfish and white marlin sensu stricto, and (4) further scenario and hypothesis testing using a variety of computer simulation approaches. Improved white marlin management and conservation policy will require refined population modeling that applies updated roundscale spearfish proportions to the historical catch data and incorporates spatial changes in fishing effort.

The decidedly declining roundscale spearfish population trend also seen in nearly all simulations indicates that management and conservation attention also needs to be focused on this enigmatic species, whose existence has only recently started to be recognized. Of additional concern is the observer data suggesting that the population size of roundscale spearfish in the western North Atlantic may be substantially smaller than that of white marlin, and that most simulations indicated even greater population declines for roundscale spearfish relative to white marlin. Without focused and possibly urgent management attention, unabated fishing pressure on roundscale spearfish may result in unrecognized population collapses that cannot be rectified by subsequent conservation efforts. The above re-assessments and new species-specific monitoring measures are essential for establishing confidence in indices of abundance and population trends for both top-level, pelagic predator species.

Acknowledgements. This study was partially funded by grant WC133F08SE2112 from NOAA Fisheries to M.S. We thank R. Horn, J. Magnussen, A. Bernard, and L. Murphy for laboratory assistance and J. Silva for creating Fig. 1.

\section{LITERATURE CITED}

Arocha F, Marcano L (2001) Monitoring large pelagic fishes in the Caribbean Sea and the western central Atlantic by an integrated monitoring program from Venezuela. Proc 52nd GCFI Meeting, Key West, FL, p 557-576

Beerkircher LR, Lee DW, Hinteregger GF (2008) Roundscale spearfish Tetrapturus georgii: updated morphology, distribution, and relative abundance in the western North Atlantic. NOAA Tech Memo NMFS 571, National Technical Information Service, Alexandria, VA

Brown LD, Cai TT, DasGupta A (2001) Interval estimation for a binomial proportion. Stat Sci 16:101-133

Collette BB, McDowell JR, Graves JE (2006) Phylogeny of recent billfishes (Xiphioidei). Bull Mar Sci 79:455-468

ICCAT (2003) Report of the 2002 ICCAT white marlin stock assessment meeting. Collect Vol Sci Pap ICCAT 55: 350-452

Jesien RV, Barse AM, Smyth S, Prince ED, Serafy JE (2006) 
Characterization of the white marlin (Tetrapturus albidus) recreational fishery off Maryland and New Jersey. Bull Mar Sci 79:647-657

Keene KF, Beerkircher LR, Lee DW (2007) SEFSC pelagic observer program data summary for 1992-2004. NOAA Tech Memo NMFS 562, National Technical Information Service, Alexandria, VA

NRC (National Research Council) (1998). Improving fish stock assessments. National Academy Press, Washington, DC

Prager MH (1994) A suite of extensions to a nonequilibrium surplus-production model. Fish Bull (Wash DC) 92: 374-389
Serafy JE, Diaz GA, Prince ED, Orbesen ES, Legault CM (2004) Atlantic blue marlin, Makaira nigricans, and white marlin, Tetrapturus albidus, bycatch of the Japanese pelagic longline fishery, 1960-2000. Mar Fish Rev 66:9-20 Shivji MS, Magnussen JE, Beerkircher LR, Hinteregger G, Lee DW, Serafy JE, Prince ED (2006) Validity, identification, and distribution of the roundscale spearfish, Tetrapturus georgii: morphological and molecular evidence. Bull Mar Sci 79:483-491

WMBRT (2007) White marlin biological review team Atlantic white marlin status review. Report to National Marine Fisheries Service, Southeast Regional Office, St. Petersburg, FL

Appendix 1. Tetrapturus albidus and T. georgii. Estimated biomass (B) trajectory and predicted yield in metric tons from the 2002 Atlantic white marlin stock assessment (ICCAT 2003)

\begin{tabular}{|c|c|c|c|c|c|c|c|c|}
\hline Year & $B$ & Yield & Year & $B$ & Yield & Year & $B$ & Yield \\
\hline 1956 & 44840 & 0 & 1972 & 23600 & 2292 & 1988 & 14840 & 1342 \\
\hline 1957 & 44820 & 179 & 1973 & 22270 & 1875 & 1989 & 14350 & 1801 \\
\hline 1958 & 44670 & 178 & 1974 & 21360 & 1780 & 1990 & 13370 & 1631 \\
\hline 1959 & 44530 & 133 & 1975 & 20540 & 1771 & 1991 & 12530 & 1710 \\
\hline 1960 & 44450 & 310 & 1976 & 19720 & 1849 & 1992 & 11580 & 1551 \\
\hline 1961 & 44180 & 832 & 1977 & 18820 & 1142 & 1993 & 10740 & 1659 \\
\hline 1962 & 43430 & 2081 & 1978 & 18610 & 967 & 1994 & 9766 & 2098 \\
\hline 1963 & 41550 & 2625 & 1979 & 18570 & 1037 & 1995 & 8284 & 1727 \\
\hline 1964 & 39280 & 3726 & 1980 & 18470 & 978 & 1996 & 7101 & 1453 \\
\hline 1965 & 36060 & 4914 & 1981 & 18430 & 1243 & 1997 & 6132 & 1189 \\
\hline 1966 & 31860 & 3507 & 1982 & 18110 & 1099 & 1998 & 6102 & 1236 \\
\hline 1967 & 29180 & 1445 & 1983 & 17950 & 1769 & 1999 & 5918 & 1199 \\
\hline 1968 & 28630 & 2048 & 1984 & 17090 & 1186 & 2000 & 5576 & 1130 \\
\hline 1969 & 27480 & 2277 & 1985 & 16820 & 1691 & 2001 & 4841 & \\
\hline 1970 & 26130 & 2144 & 1986 & 16030 & 1523 & & & \\
\hline 1971 & 24920 & 2279 & 1987 & 15380 & 1405 & & & \\
\hline
\end{tabular}

Appendix 2. Tetrapturus albidus and T. georgii. Observed effort (no. hooks), number of white marlin (WHM) and roundscale spearfish (RSS) observed, and proportion of RSS with associated $95 \%$ confidence intervals (CI) for each data set and area used in the present study. See Fig. 1 for abbreviations and Fig. 2 for area subsets. NA: not applicable

\begin{tabular}{|c|c|c|c|c|c|c|}
\hline Area & Data subset & Effort & No. of fish & Prop. RSS & Lower $95 \%$ CI & Upper $95 \% \mathrm{CI}$ \\
\hline CAR & US1 & 19215 & 17 & 0.12 & 0.03 & 0.34 \\
\hline CAR & US2 & 14516 & 1 & 0.00 & 0.00 & 0.79 \\
\hline CAR & VZL & 996522 & 828 & 0.34 & 0.31 & 0.37 \\
\hline FEC & US1 & 6320 & 8 & 1.00 & 0.68 & 1.00 \\
\hline FEC & US2 & 78495 & 53 & 0.30 & 0.20 & 0.44 \\
\hline GOM & US1 & 9721 & 7 & 0.00 & 0.00 & 0.35 \\
\hline GOM & US2 & 991807 & 89 & 0.00 & 0.00 & 0.04 \\
\hline MAB & US2 & 112046 & 22 & 0.09 & 0.03 & 0.28 \\
\hline MAB & WMO & NA & 26 & 0.31 & 0.17 & 0.50 \\
\hline $\mathrm{NCA}$ & US1 & 14616 & 10 & 1.00 & 0.72 & 1.00 \\
\hline NCA & VZL & 8100 & 3 & 0.00 & 0.00 & 0.56 \\
\hline NEC & US1 & 35154 & 20 & 0.35 & 0.18 & 0.57 \\
\hline NEC & US2 & 11044 & 13 & 0.54 & 0.29 & 0.77 \\
\hline NED & US2 & 38468 & 4 & 1.00 & 0.51 & 1.00 \\
\hline SAB & US1 & 16317 & 26 & 0.19 & 0.09 & 0.38 \\
\hline SAB & US2 & 52576 & 10 & 0.40 & 0.17 & 0.69 \\
\hline SAR & US1 & 16225 & 37 & 0.86 & 0.72 & 0.94 \\
\hline SAR & US2 & 7660 & 7 & 0.86 & 0.49 & 0.97 \\
\hline SAR & VZL & 91260 & 52 & 0.02 & 0.00 & 0.10 \\
\hline TUN/TUS & US1 & 13346 & 124 & 0.00 & 0.00 & 0.03 \\
\hline TUN/TUS & US2 & 24720 & 18 & 0.11 & 0.03 & 0.33 \\
\hline TUN/TUS & VZL & 19061 & 68 & 0.01 & 0.00 & 0.08 \\
\hline
\end{tabular}

